J. Rychlý, K. Mosnáčková, L. Rychlá, A. Fiedlerová, Gy. Kasza, A. Nádor, Zs. Osváth, T. Stumphauser, Gy. Szarka, K. Czaníková, S. Chmela, B. Iván, J. Mosnáček Comparison of the UV stabilisation effect of commercially available processing stabilizers Irganox HP 136 and Irganox 1010

POLYMER DEGRADATION AND STABILITY 118: pp. 10-16. (2015)

"This accepted author manuscript is copyrighted and published by Elsevier. It is posted here by agreement between Elsevier and MTA. The definitive version of the text was subsequently published in Polymer Degradation and Stabilitity 118, pp. 1016, 2015, doi:10.1016/j.polymdegradstab.2015.04.007. Available under license CCBY-NC-ND."

\title{
Comparison of the UV stabilisation effect of commercially available processing stabilizers Irganox HP 136 and Irganox 1010
}

Jozef Rychlýa ${ }^{a^{*}}$, Katarina Mosnáčkováa, Lyda Rychláa, Agnes Fiedlerováa, György Kasza $^{\mathrm{b}}$, Attila Nádor ${ }^{\mathrm{b}}$, Zsófia Osváth ${ }^{\mathrm{b}}$, Timea Stumphauser ${ }^{\mathrm{b}}$, Györgyi Szarka ${ }^{\mathrm{b}}$, Klaudia Czaníkováa ${ }^{\mathrm{a}}$ Stefan Chmela ${ }^{\mathrm{a}}$, Béla Iván ${ }^{\mathrm{b}}$, Jaroslav Mosnáček ${ }^{\mathrm{a}}$

a Polymer Institute, Slovak Academy of Sciences

84541 Bratislava, Dúbravská cesta 9, Slovakia

b Polymer Chemistry Research Group, Institute of Materials and Environmental Chemistry, Research Centre for Natural Sciences, Hungarian Academy of Sciences H-1117 Budapest, Magyar tudósok körútja 2, Hungary

* Corresponding author.

E-mail address: upoljory@savba.sk

\begin{abstract}
Infrared and UV spectroscopy were used for estimation and mutual comparison of action of Irganox HP 136 and Irganox 1010 in UV stabilisation of polypropylene films. The instantaneous stability state of polypropylene after the different time of UV treatment was also tested by the non-isothermal chemiluminescence so that the actual
\end{abstract}


resistance of sample against the thermal oxidation has been established. It was ascertained that Irganox HP 136 as aweak thermo-oxidation stabiliser is an excellent UV stabiliser of polypropylene, the fact that was not described in the literature until now. This stabilising efficiency was proposed to be provided by photochemical transformation of Irganox HP 136 to 2-hydroxy benzophenone moieties, the compound with ability to absorb the light as well as efficiently scavenge reactive free radicals.

\section{Keywords:}

Polypropylene Increased UV stability due to Irganox HP136 Chemiluminescence FTIR spectroscopy 


\section{Introduction}

There exist a lot of data in the literature on the stabilisation of polypropylene against the harmful effect of heat and light. Regardless of it there still exists the search for not fully explored propertiesofalreadyknownadditives.Thismaybeexemplified,e.g. on the so-called capto-dative lactones of the benzofuranone type that are used as the polypropylene processing stabilisers [1,2]. Irganox HP 136 may be a representative example. The stabilizing effect of benzofuranones is based on their ability to scavenge both carbon- and oxygen-centred radicals [3,4] converting them to the less efficient free radical sites situated at the lactone ring.

The thermooxidation stabilizing efficiency of benzofuranones is usually weak. Antioxidants based on sterically hindered phenols like Irganox 1010 are, however, much more effective. Todaya lot of benzofuranones with different chemical structures have been synthesized $[5,6]$ and the combined antioxidants composed of benzofuranones and conventional stabilizers have been widely used also as excellent antioxidants for polymers [7]

In our last paper a significant pro-degradation effect due to UV lighthasbeenshown for 2,5-bis(2-furylmethylene)cyclopentanone $\left(\mathrm{F}_{2} \mathrm{C}\right)$ [8]. On the other hand, $\mathrm{F}_{2} \mathrm{C}$ acted as excellent thermoxidation stabiliser.

The present paper is focused on evaluation of photostabilisation action of Irganox HP 136 in polypropylene and on its comparison with the effect of Irganox 1010.

The light absorption by the polymer initiate the formation of free radicals that initiate the oxidation of the polymer. The antioxidants used may then either scavenge these free radicals or decompose hydroperoxides formed as it is common in thermal stabilization. The additional effect may be linked with the nonharmful absorption of light (UV absorber) or with their photosensitizing action. The possibility that the 
additive is converted by the light to both the photostabiliser and thermal stabilizer appears to be case of Irganox HP 136.

\section{Experimental}

\subsection{Chemicals}

Structures of antioxidants are seen in Schemes 1 and 2.

Polypropylene was Tatrene TF 550, product of Slovnaft Bratislava, powder, free of stabilizers. Two polypropylenes were used differing in melt flow indices in stabilization experiments. Their behaviour in UV initiated oxidation was compared expecting that polypropylene with lower molar mass will be oxidized easier as it contains higher concentration of terminal unsaturations. This assumption was based on results from paper [9] where we have found it for thermal oxidation of fractionated Repsol polypropylene. However, as it may be seen from Fig. 1 in the present case both polypropylene oxidize with the same kinetics, approximately.

The polypropylene films from both kinds of the polymer having 0.1 and $0.2 \%$ wt. of Irganox 1010 and 0.15 and $0.3 \%$ wt. ofIrganox HP 136 were prepared byblending acetone solution of an additive and polypropylene to receive molar concentrations of reactive groups corresponding $8.5 \times 10^{-4}$ and $1.7 \times 10^{-3} \mathrm{~mol} / \mathrm{kg}$ for Irganox 1010 and $4.3 \times 10^{-3}$ and $8.5 \times 10^{-3} \mathrm{~mol} \mathrm{~kg}^{-1}$ of Irganox HP 136.Provided that Irganox 1010 contains 4 reactive phenoxyl groups in 1 molecule while functionality of Irganox HP 136 appears to be 1 the molar concentration of reactive groups of $0.1 \%$ of Irganox 1010 corresponds to $0.15 \%$ of Irganox HP136 and equals to $3.5 \times 10^{-3}$ equivalents of reactive phenoxyls related to $1 \mathrm{~kg}$ of polymer. The polymer itself and that with an additive was homogenized in the chamber of Plastograph Brabender at $190{ }^{\circ} \mathrm{C}$ at $40 \mathrm{rp} / \mathrm{min}$ for $5 \mathrm{~min}$ and then pressed at $180{ }^{\circ} \mathrm{C}$. The thickness of the film was around $100 \mathrm{~mm}$. 


\subsection{Photooxidation}

The samples were exposed to UV irradiation in a merry-goround type setup. The irradiation source was a medium pressure $250 \mathrm{~W}$ mercury arc with luminophore envelope (RVL, Tesla Hole-sovice, Czech Republic) with wavelengths above $310 \mathrm{~nm}$. The temperature of photo-oxidation was $30{ }^{\circ} \mathrm{C}$. Sample films, fixed on aluminium holders, turned around the UV lamp in air. The films were irradiated for various exposure times from 0 to $1600 \mathrm{~h}$.

The FTIR spectra $\left(4000-400 \mathrm{~cm}^{-1}\right)$ were obtained with a Nicolet 6700 FTIR spectrometer. 128 scans with a resolution $4 \mathrm{~cm}^{-1}$ have been registered with the use of OMNIC software (Thermo Instruments Corp.).

Absorption spectra were recorded on a spectrometer UV 1650PC (Shimadzu, Japan).

\subsection{Chemiluminescence}

Chemiluminescence measurements, which were used for the testing of the momentaneous state of sample exposed to UV oxidation were performed in a Lumipol 3 photon-counting instrument manufactured at the Polymer Institute of the Slovak Academy of Sciences. The film samples (from 5 to $7 \mathrm{mg}$ ) were weighed on an aluminium pan ( $9 \mathrm{~mm}$ in diameter) and placed in the sample compartment. The gas flow (oxygen or nitrogen) through thesample cellwasset to.3.0 $\mathrm{Lh}^{-1}$.The purgingof the gas through the compartment was set $10 \mathrm{~min}$ before the start of measurement. The temperature in the sample cell of the apparatus increased linearly with time from $40{ }^{\circ} \mathrm{C}$ up to $220{ }^{\circ} \mathrm{C}$, at the rate $5{ }^{\circ} \mathrm{C}$. $\min ^{-1}$. The signal of the photocathode was recorded at a 10-second data collection interval. Repeated experiments do not differ on the temperature axis more than by $1{ }^{\circ} \mathrm{C}$ and by $5 \%$ in chemiluminescence intensity. 
Nonisothermal chemiluminescence experiments were presented as chemiluminescence intensity signal vs. temperature or time. The latter presentation has its advantage in resemblance to induction time from isothermal assessment of polymer stability. It might be of interest also when one attempts to differentiate the behaviour of respective additives after ramping temperature of $220{ }^{\circ} \mathrm{C}$.

\section{Results and discussion}

The evolution of the carbonyl peak at $1730 \mathrm{~cm}^{-1}$ of polypropylene additivated with Irganox 1010 and Irganox HP 136 during UV irradiation from 0 to $1500 \mathrm{~h}$ may be seen in Fig. 2.

One can be rathersurprised bythe high efficiencyof Irganox HP 136 in stabilization of polypropylene towards UV irradiation (Fig. 2). From the evolution of the carbonyl peak at $1730 \mathrm{~cm}^{-1}$, Irganox HP136 in polypropylene was quite competitive with Irganox 1010 (Fig. 3) for which the UV stabilization is mainly based on the scavenging of free radicals appearing there due to UV initiation. From Fig. 3 we may also see that the content of Irganox HP 136 in polypropylene above $0.15 \%$ wt. does not lead to further increase of the induction time of oxidation.

On the other hand, when performing only thermo-oxidation test we may notice that the difference in thermo-oxidation stability of polypropylene in oxygen as measured by chemiluminescence (Fig. 4) due to antioxidation effect of Irganox 1010 when compared with Irganox HP 136 is much more significant. At the same time, Irganox HP 136 at concentration $0.3 \%$ wt. does not show further increase of stabilizing efficiency similarly as in infrared spectroscopy measurements and UV irradiation. This might be explained by the tendency to the nivelization of stabilizer efficiency when approaching upper limit of its concentration in solid polymer. The authors [10] explain it by the limiting 
solubility and also by the change in reactivity of antioxidant in solid polymer when compared to solution.

The chemiluminescence intensity of polypropylene after the consumption of the stabiliser is more over higher for polypropylene containing Irganox HP 136 than that for polypropylene containing Irganox 1010 (Fig. 5) indicating thus that peroxyl radicals derived from Irganox HP 136 may also come into the play (Scheme 3).

In Fig. 6 we may see the interesting fluctuations in the position of chemiluminescence-time ramping records. Non-irradiated sample is the most stable, the steadily decreasing stability may be observed for samples irradiated for 115, 280 and $370 \mathrm{~h}$ while after $470 \mathrm{~h}$ of UV irradiation the chemiluminescence-temperature line again approaches to that for non-stabilized sample. This tendency turns out after $975 \mathrm{~h}$ of sample irradiation which should be linked with consumption of the stabilizer and appearance of hydroperoxidic peak A in nitrogen measurements (Fig. 7). Part B of the chemiluminescence nitrogen records should be linked with luminosity of polypropylene at temperatures above $200{ }^{\circ} \mathrm{C}$ due to recombination of free radicals coming out from defect polypropylene structures [11].

At the same time, in nitrogen, the peroxidic peak having the maximum at $140{ }^{\circ} \mathrm{C}$, becomes distinct after this time of irradiation (Fig.7). We have to remind that each line is the average from 3 runs differing by $1^{\circ}$ in the maximum rate of increase of the CL run, so that this tendency appears to be evident.

An interesting observation can be seen on chemiluminescence temperature runs in nitrogen after lower irradiation times. When compared with non-irradiated samples, the chemiluminescence intensity e temperature line moves to the right at around ramping temperature (until $380 \mathrm{~h}$ ) and then shifts back to lower temperatures. This may be the indication that a light stabilizer is stepwisely formed during irradiation. Because of very 
good resistance of polypropylene samples with Irganox HP 136 against UV light, the mechanism may be assessed, namely that benzofuranone lactone in the oxidized polymer converts to the 2-hydroxy benzophenone derivative which is rather efficient stabilizers against the effect of light (Scheme 3).

The Scheme 3 explains the whole sequence of presumed reactions during the irradiation Irganox HP 136 in polypropylene in air. In the step 1 hydrogen is abstracted from the b-position of the carbonyl group by alkyl or peroxyl radicals. Radicals B terminate with peroxyl radicals (step 2) and dialkyl peroxide in the step 3 splits to carbon monoxide and alkoxyl radicals and 2-hydroxy benzophenone derivative is formed with sterically hindered phenoxyls (step4). This adequately should explain the relative changes in thermo-oxidation stability of polypropylene (Figs. 6 and 7) as well as photostabilisation effect due to Irganox HP 136. The presence of other kind of peroxyl radicals such as BOO may be presumed from the higher light intensities of polypropylene with Irganox HP 136 than that with Irganox 1010 (Fig. 4).

As it is not easy to adopt a definite conclusion because of low concentration of additive in polypropylene there are some indications that it might be so from the record of UV spectra of irradiated polypropylene containing Irganox HP136 in the interval of wavelength 240-400 nm (Fig. 8).

Two broad maxima, the one at $270 \mathrm{~nm}$ and the second at $276 \mathrm{~nm}$ and shoulders at $284 \mathrm{~nm}$ and $351 \mathrm{~nm}$ were observed. Both bands steadily increase with the time of irradiation achieving relatively fast some saturated level. We tempt to link themwith the progress of polypropylene oxidation. From the literature data for pure 2hydroxybenzophenone in ethanol the UV bands at $260 \mathrm{~nm}$ and $337 \mathrm{~nm}$ were observed; the first band being attributed to $\pi-\pi^{*}$ transitions and the second to intramolecular charge transfer (CT) between 2-hydroxyl and carbonyl group [12]. At the same time, it 
was ascertained that the positions of both bands is affected by substituents. As it follows from Fig. 8, the CT complex between carbonyl and 2-hydroxyl may be represented by the shoulder at $351 \mathrm{~nm}$.

\section{Conclusions}

Irganox HP 136 commonly used as processing stabilizer and weak antioxidant was found to be rather efficient UV stabilizer of polypropylene. The mechanism of its action is probably based on the sequence of free radical transfer and fragmentation reactions leading to the 2-hydroxy benzophenone derivative joining the properties of the light absorber (carbonyls of benzophenone) and free radicals scavenger due to sterically hindered 2-hydroxy groups.

\section{Acknowledgements}

The authors thank for financial support to the European Regional Development Fund through the Hungary-Slovakia Cross Border Cooperation Program 2007-2013 (HUSK/1101/1.2.1/0209) and Grant Agency VEGA, projects No. 2/0147/12 and 2/0161/14.

\section{References}

[1] Mar'in A, Greci L, Dubs P. Antioxidant activity of 3-aryl-benzofuran-2-one stabilizers (Irganox HP-136) in polypropylene. Polym Degrad Stab 2002;76:489-94.

[2] Mar'in A, Greci L, Dubs P. Physical behavior of 3-aryl-benzofuran-2-one (IrganoxHP-136) in polypropylene. Polym Degrad Stab 2002;78:263-7.

[3] Meng Xin, Xin Zhong, Wang Xue-feng. Structure effect of benzofuranone on the antioxidant activity in polypropylene. Polym Degrad Stab 2010;95:2076-81. 
[4] Voigt W, Todesco R. New approaches to the melt stabilization of polyolefins. Polym Degrad Stab 2002;77:397-402.

[5] Meng Xin, Gong Weiguang, Xin Zhong, Cai Zhi. Study on the antioxidant activities of benzofuranones in melt processing of polypropylene. Polym Degrad Stab 2006;91:2888-93.

[6] Solera P. New trends in polymer stabilization. J Vinyl Addit Technol 1998;4(3): 197-210.

[7] Pospisil J, Nespurek S. Chain-breaking stabilizers in polymers: the current status. Polym Degrad Stab 1995;49:99-110.

[8] Rychlý J, Rychlá L, Fiedlerová A, Chmela S, Hronec M. Thermally and UV initiated degradation of polypropylene in the presence of 2,5 bis(2furylmethylene) cyclopentanone and heterogeneous distribution of hydroperoxides assessed by nonisothermal chemiluminescence in nitrogen. Polym Degrad Stab 2014;108:41-7.

[9] Rychly J, Matisova-Rychla L, Tiemblo P, Gomez-Elvira J. The effect of physical parameters of isotactic polypropylene on its oxidisability measured by chemiluminescence method. Contribution to the spreading phenomenon. Polym Degrad Stab 2001;71:253-60.

[10] Shlyapintokh V Ya. Nivelization of the reactivity of stabilizers in solid polymers. in Russian. In: Photochemical transformation and stabilization of polymers. Publishing House Khimyia; 1979. p. 46.

[11] Koutny M, Vaclavkova T, Matisova-Rychla L, Rychly J. Characterization of oxidation progress by chemiluminescence: a study of polyethylene with prooxidant additives. Polym Degrad Stab 2008;93:1515-9.

[12] Hrdlovic P, Bellus D. Effect of substituents on ultraviolet absorption spectra of derivatives of o-hydroxybenzophenone. Chem Zvesti 1968;22:508-13. 


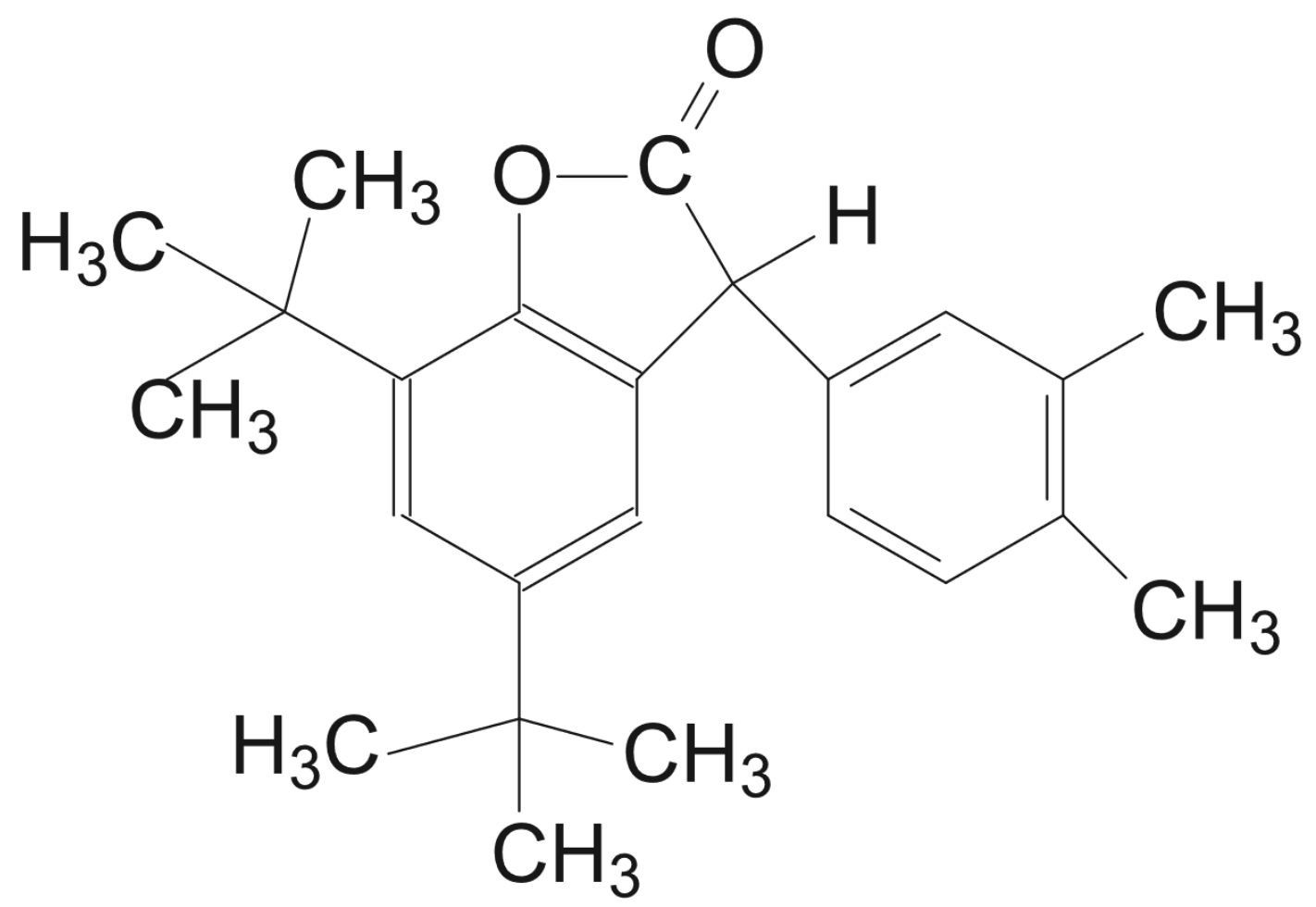

Scheme 1. Irganox HP 136 - mixture of $90 \%$ of 5,7-di-tert-butyl-3 (3,4dimethylphenyl)3H-benzofuran-2-one (See the structure above) and 10\% of 5,7ditert-.butyl-3-(2,3-dimethylphenyl)3H-benzofuran-2-one. The average molar mass of this blend was $400 \mathrm{~g} / \mathrm{mol}$, approximately. 


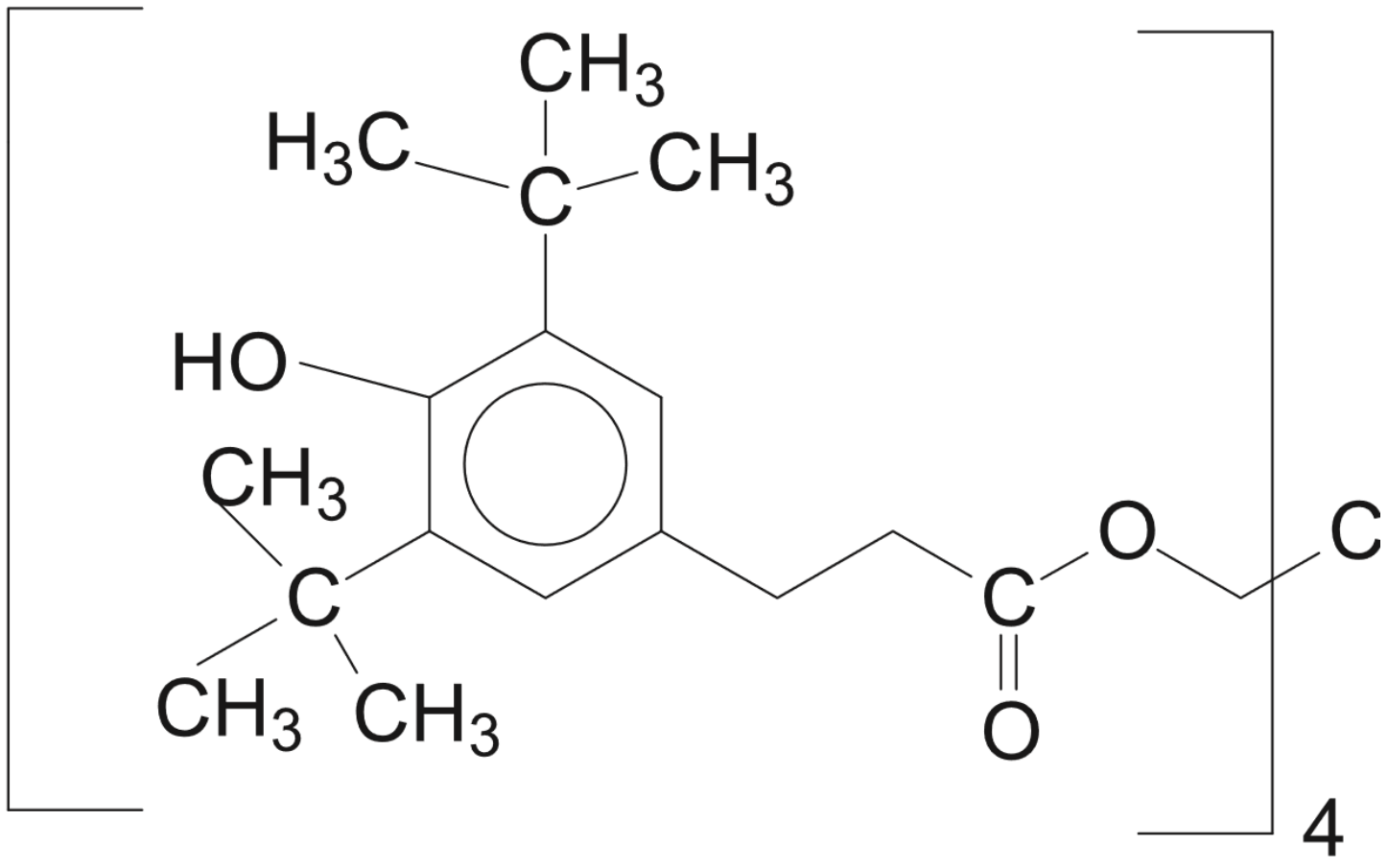

Scheme 2. Structure of Irganox 1010. Irganox 1010 - Pentaerythritol tetrakis (3-(3,5ditert-butyl-4-hydroxyphenyl) propionate was purchased from Ciba Specialty Chemicals. The molar mass of Irganox 1010 is $1178 \mathrm{~g} / \mathrm{mol}$. 
<smiles>Cc1ccc(C2C(=O)Oc3c2cc(C(C)(C)C)cc3C(C)(C)C)cc1C</smiles><smiles>Cc1ccc([C@H]2C(=O)Oc3c2cc(C(C)(C)C)cc3C(C)(C)C)cc1C</smiles><smiles>Cc1ccc([C@H]2C(=O)Oc3c2cc(C(C)(C)C)cc3C(C)(C)C)cc1C</smiles><smiles>[R]OC1(c2ccc(C)c(C)c2)C(=O)Oc2c(C(C)(C)C)cc(C(C)(C)C)cc21</smiles>
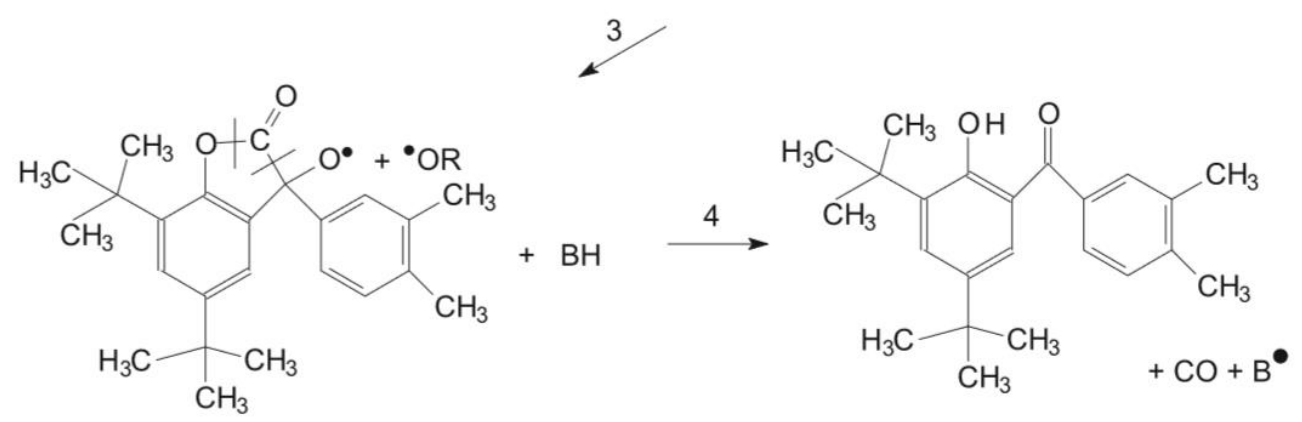

Scheme 3. The sequence of free radical reactions leading to 2-hydroxy benzophenone derivative, the compound with stabilizing effect against the light. 


\section{FIGURES}

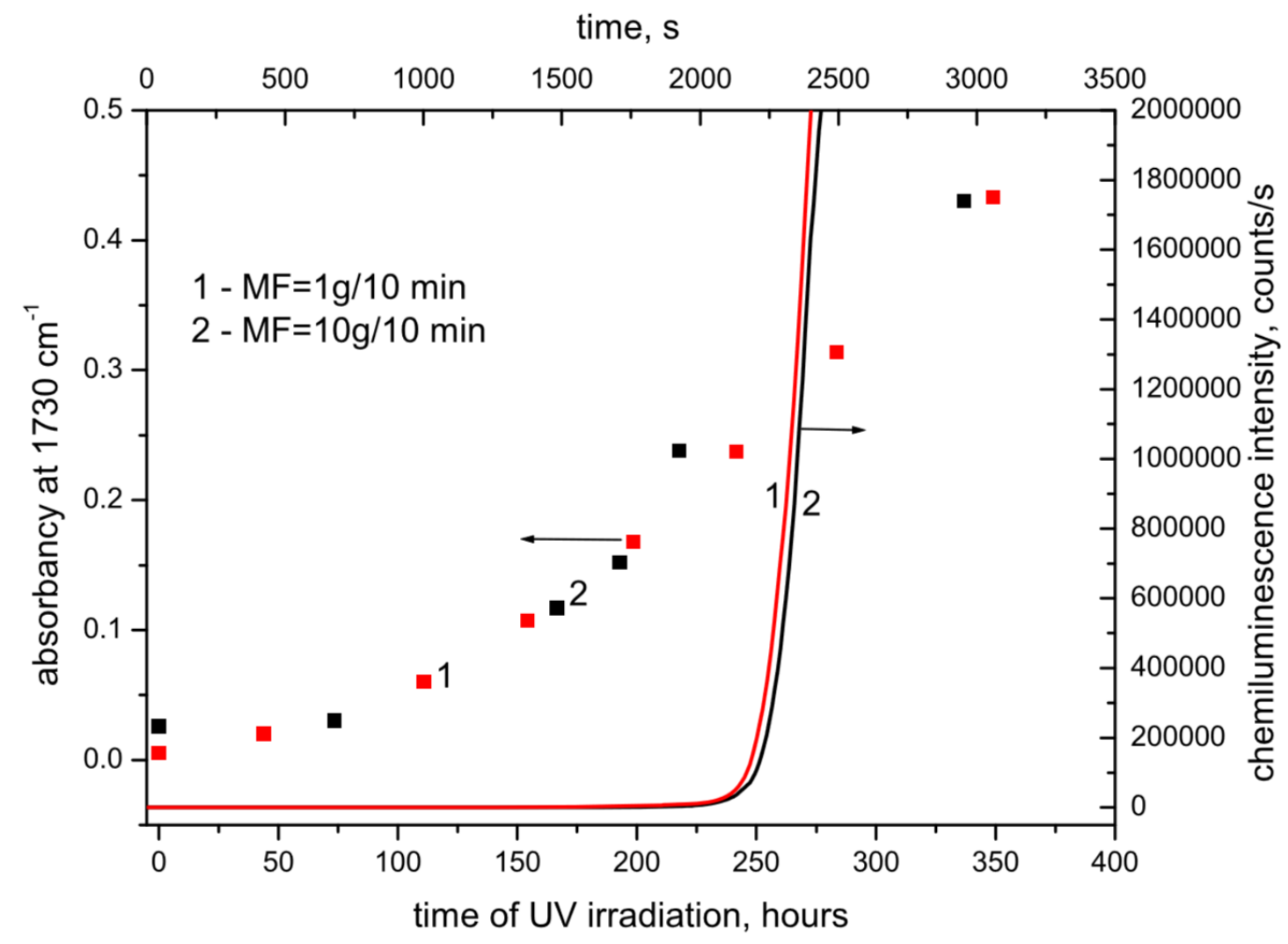

Fig.1. The changes of carbonyl peak intensity during irradiation of two kinds of pure polypropylene differing in melt flow indices (points) and chemiluminescence intensity runs testing their thermal oxidation in oxygen (lines). Chemiluminescence has been measured in oxygen in the ramp experiment keeping sample first $10 \min (600 \mathrm{~s})$ at 40 ${ }^{\circ} \mathrm{C}$ and then increasing the temperature by the rate $5^{\circ} \mathrm{C} / \mathrm{min}$ to $220{ }^{\circ} \mathrm{C}$. 


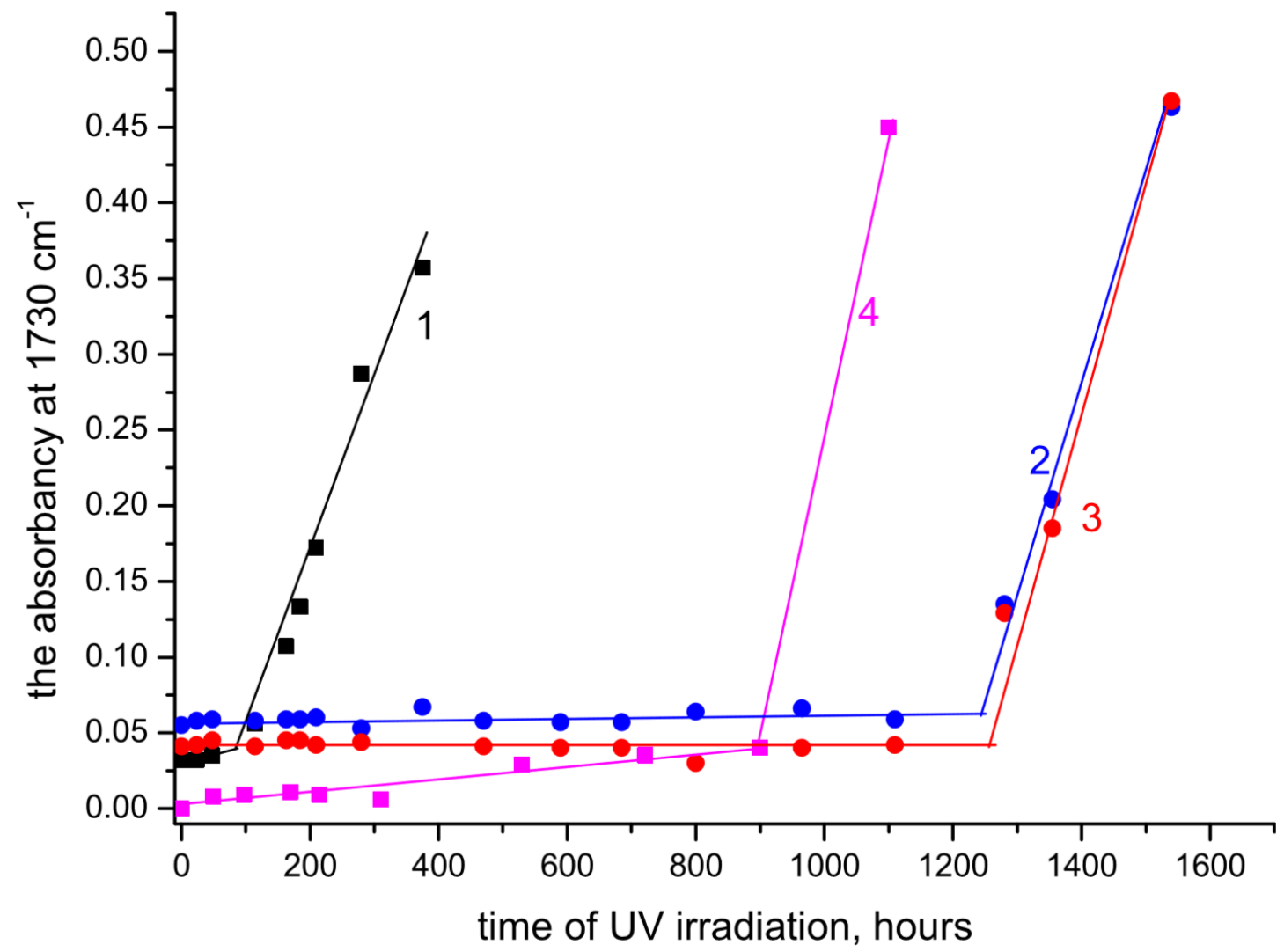

Fig. 2. The evolution of the height of the carbonyl peak (FTIR) at $1730 \mathrm{~cm}^{-1}$ during UV irradiation of polypropylene (MF=10 g/10 min) containing Irganox HP136 and Irganox 1010. The line 1-purePP, line 2-0.15\%wt. of Irganox HP136, line 3-0.3\%wt. of Irganox HP136, line 4-0.1\% wt. of Irganox 1010. 


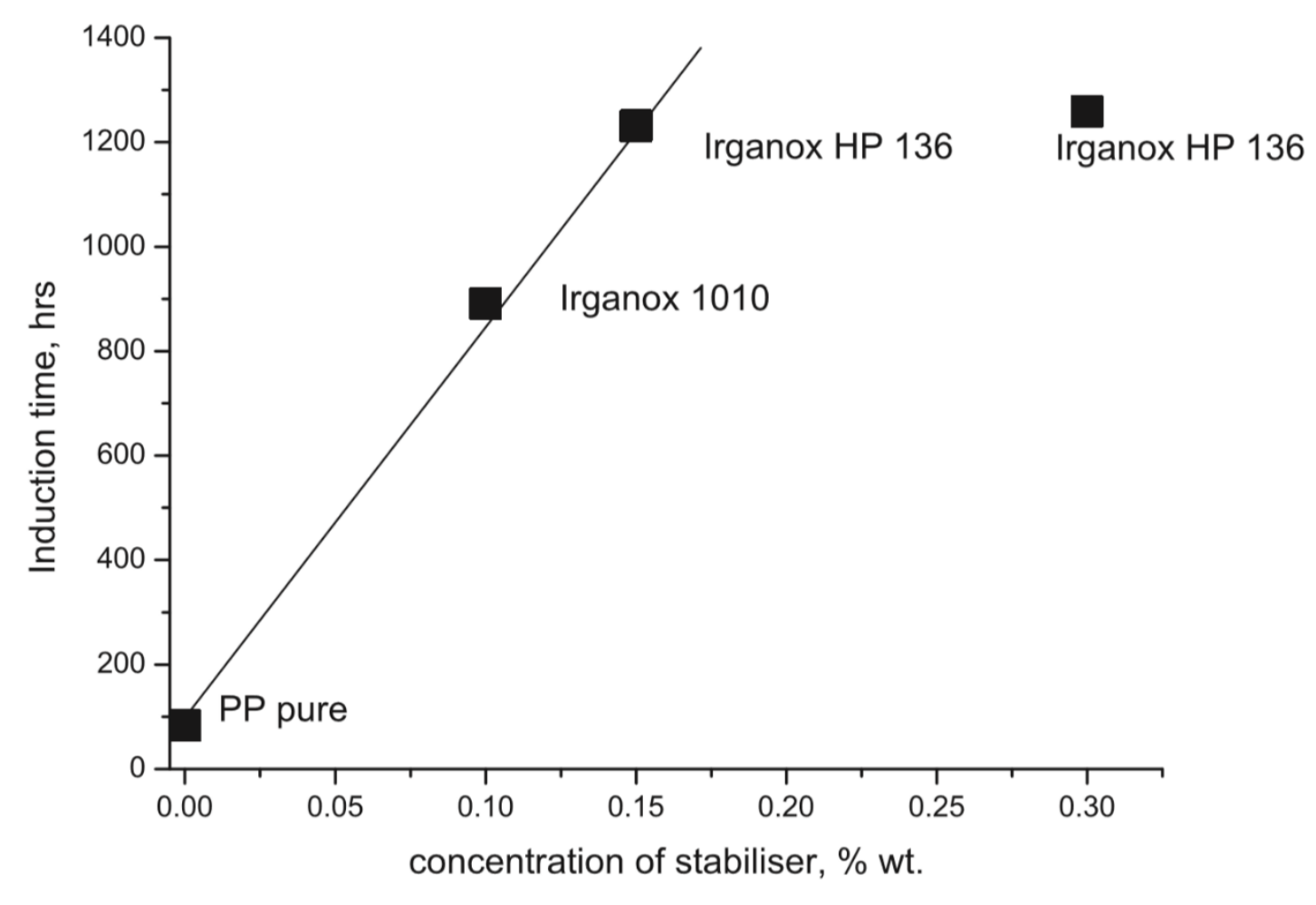

Fig. 3. The plot of induction time from infrared spectroscopy measurements for evolution of carbonyl absorption vs. concentration of a stabilizer. 


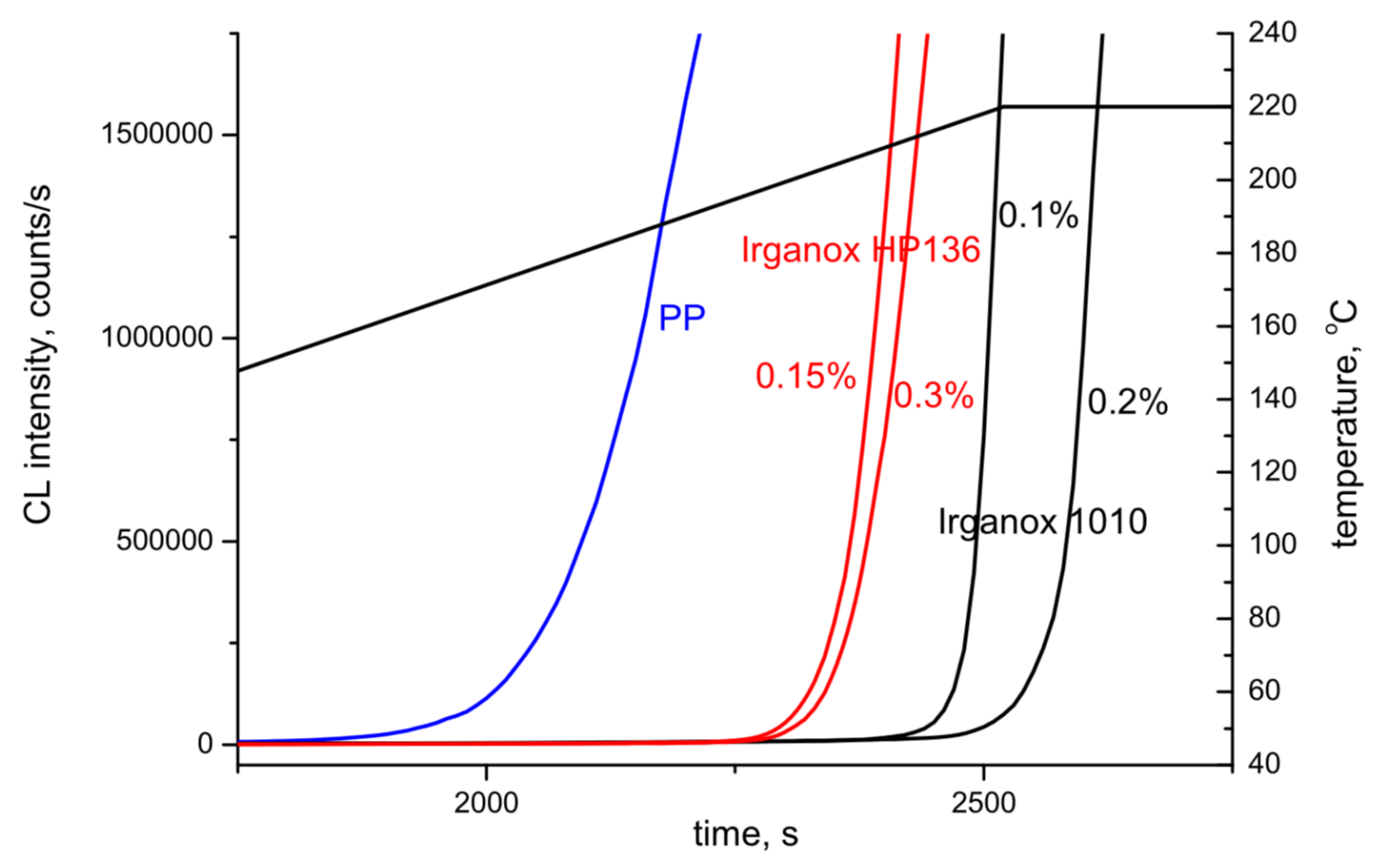

Fig. 4. Chemiluminescence runs for $P P(M F=10 \mathrm{~g} / 10 \mathrm{~min}$ ) oxidized in oxygen, the rate of heating $5{ }^{\circ} \mathrm{C} / \mathrm{min}$. The temperature profile from 130 to $220{ }^{\circ} \mathrm{C}$ belongs to the right axis. 


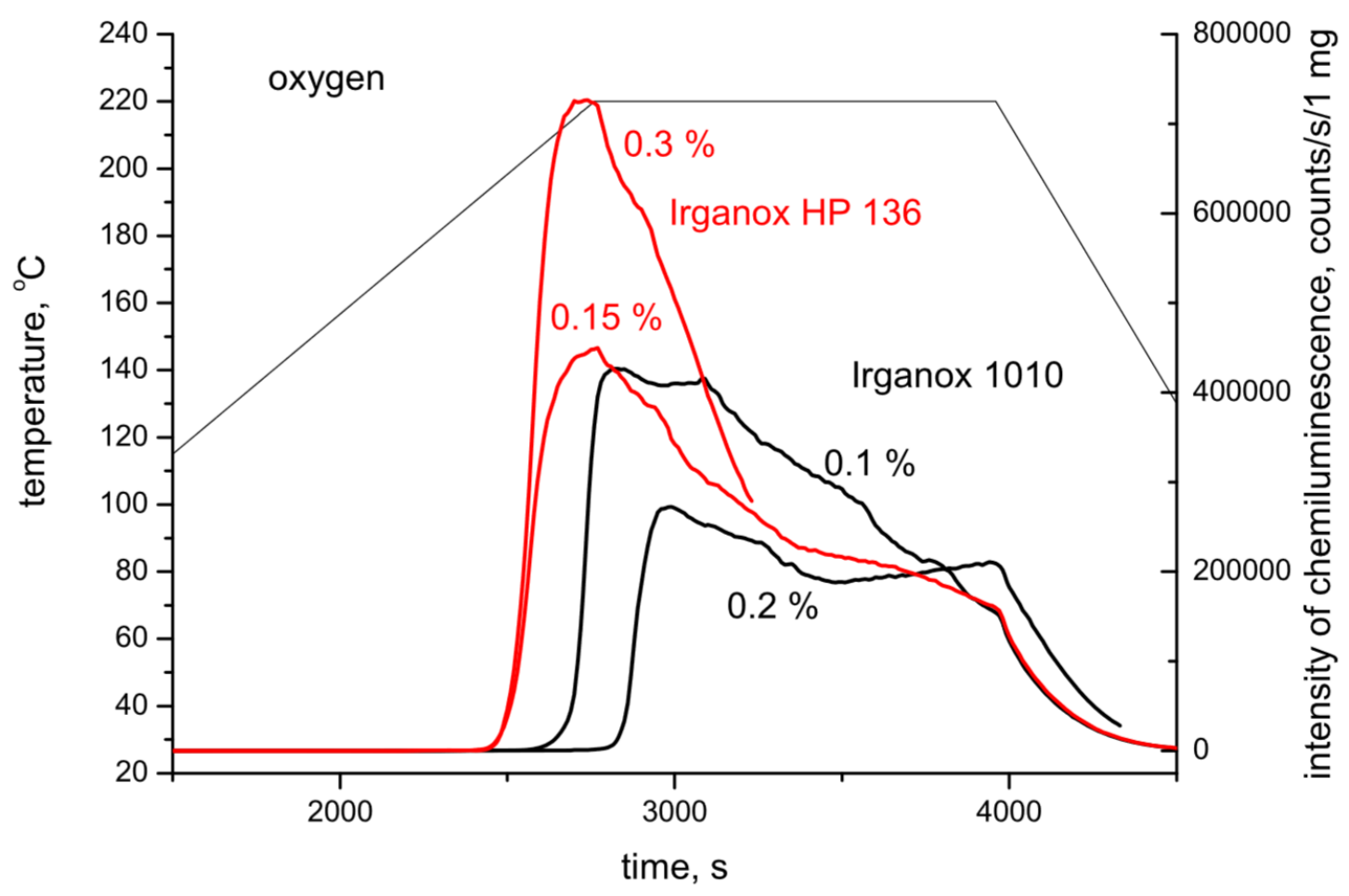

Fig. 5. Comparison of oxidisability of polypropylene stabilized with Irganox HP 136 and Irganox 1010. The rate of sample heating from 40 to $220{ }^{\circ} \mathrm{C}$ was $5{ }^{\circ} \mathrm{C} / \mathrm{min}$. 


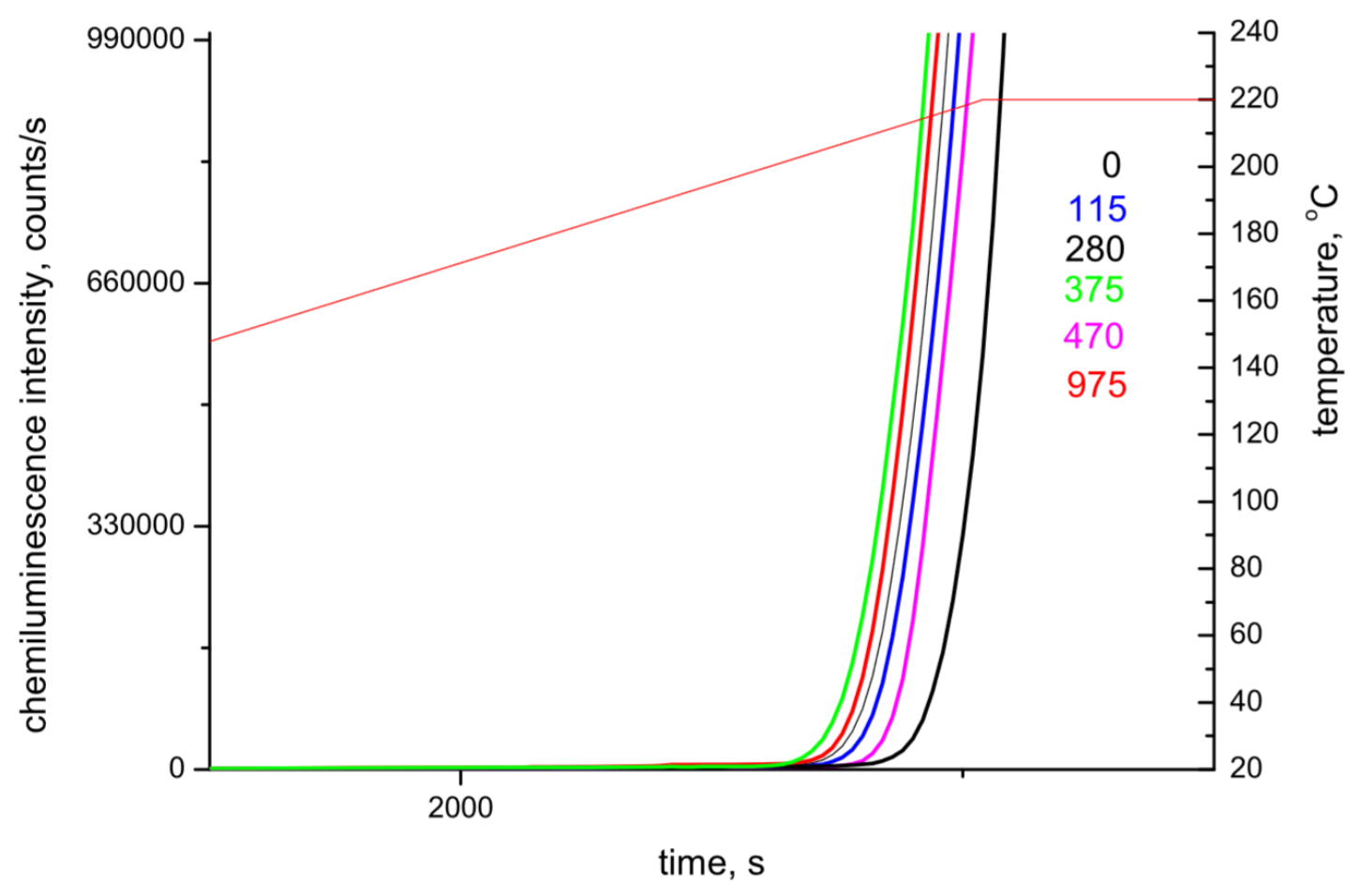

Fig. 6. Chemiluminescence intensity runs in oxygen (the rate of heating $5{ }^{\circ} \mathrm{C} / \mathrm{min}$ ) for polypropylene $(\mathrm{MF}=10 \mathrm{~g} / 10 \mathrm{~min})$ with $0.15 \%$ wt. of Irganox HP136 irradiated in air. The numbers denote the time of irradiation in hours. 


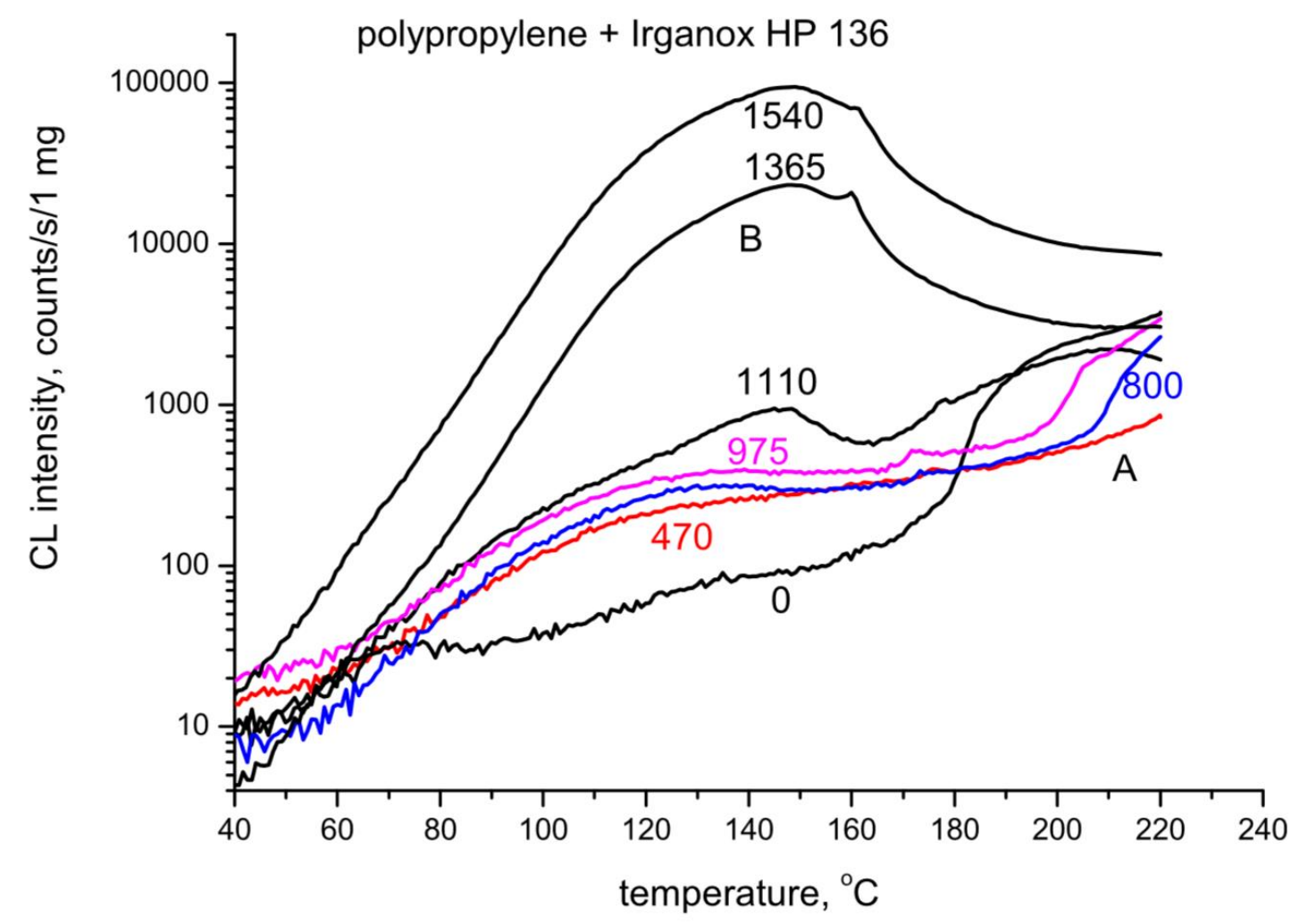

Fig. 7. Chemiluminescence intensity runs in nitrogen for polypropylene (MF $=10 \mathrm{~g} / 10$ min) with $0.15 \%$ wt. of Irganox HP136 irradiated in air. The numbers denote the time of irradiation in hours. 


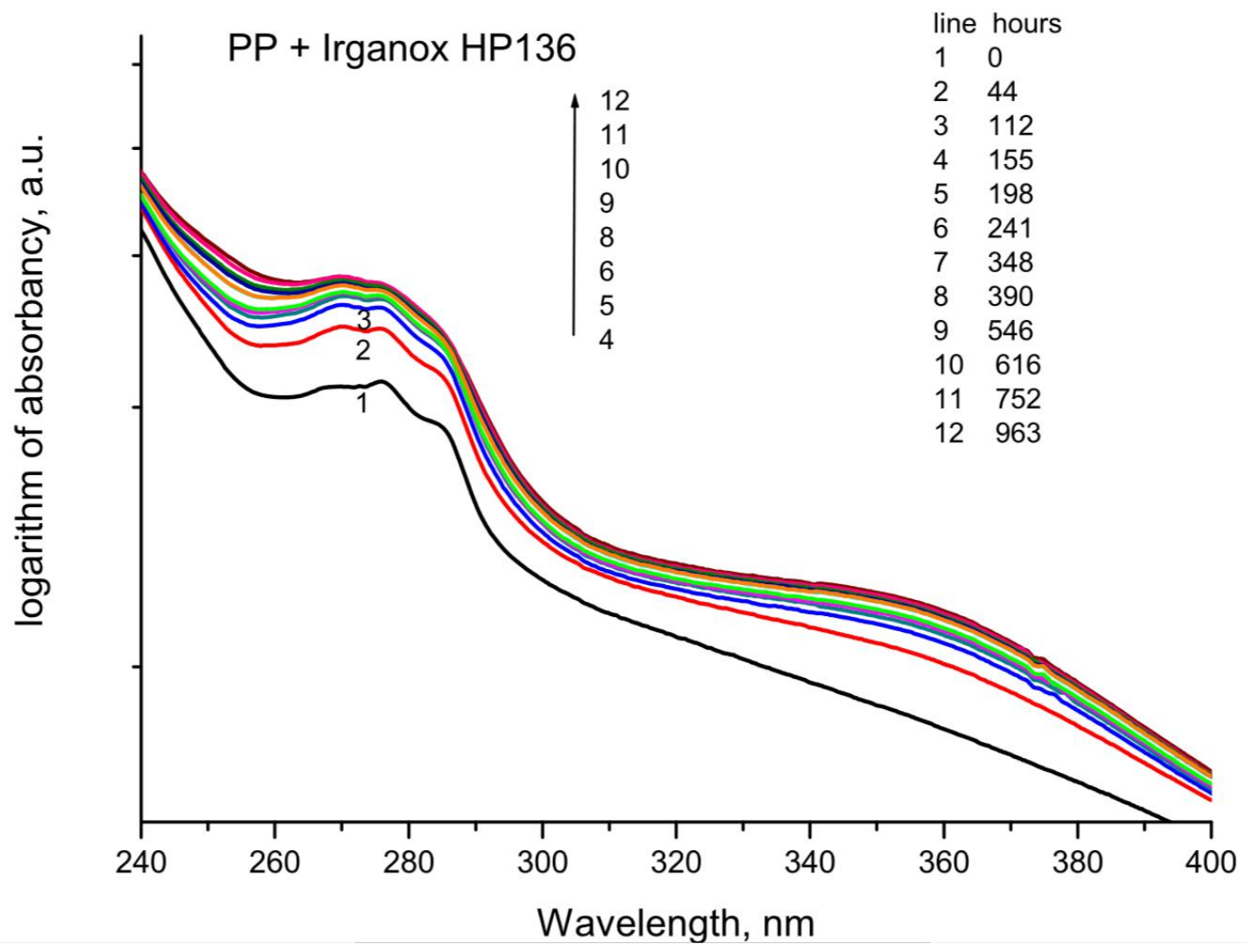

Fig. 8. The changes of absorbancy from 240 to $400 \mathrm{~nm}$ for polypropylene (MF $=1 \mathrm{~g} / 10$ min) and Irganox HP136 (0.15\% wt.) with time of UV irradiation. 